Makale türü / Article type: Araştırma / Research

\title{
Sosyal Sermaye Ürünü Olarak Taziye Kültürü ve Kurumsal Bir Hizmet Olarak Yas Danışmanlığı: Türkiye-Almanya Örneği
}

$* * *$

\section{Condolence Culture as a Product of Social Capital and Grief Counseling as an Institutional Service: The Examples of Turkey and Germany}

\author{
Doç. Dr. İsmail Barış \\ ORCID (0000-0001-8371-1243) \\ Öğr. Gör. Emine Ataman
}

Üsküdar Üniversitesi, Sağlik Bilimleri Fakültesi, ismail.baris@ uskudar.edu.tr

Artvin Çoruh Üniversitesi, Borçka Acarlar Meslek Yüksekokulu, emineataman@artvin.edu.tr ORCID (0000-0002-6057-7499)

\section{Özet}

Bir sosyal sermaye birikimi olarak değerlendirilen taziye kültürü, Türk geleneğinde büyük önem arz etmektedir. Taziye kültürünün yas sürecindeki bireylerde psikolojik, sosyal ve manevi bakımdan teskin edici, yatıştırıcı ve iyileştirici bir etkisi olduğu bilinmektedir. Almanya'da taziye merasimleri, sınırlı sayıda aile mensubu ve yakın çevre tarafından icra edilmektedir. Ancak Almanya'da özellikle hastanelerde ve yaşlı bakım merkezlerinde terminal (tedavisi olmayan) hastalıklara yakalanmış hasta ve ailelerine yönelik profesyonel yas danışmanlığı hizmeti yaygındır. Ölüme refakat/destek hizmeti ve yas danışmanlığının gayesi, ölecek kişiye manevi bakım ve rehberlik sağlamak suretiyle ölümün fiziki ve psikolojik sıkıntılarını hafifletmektir. Almanya'daki bütün hastalar insan onuruna yaraşır ölüme refakat hizmetleri ve yas danışmanlığı alma hakkına sahiptir. Her ne kadar Türkiye'de yas danışmanlığı henüz mesleki/kurumsal şekliyle oluşmamış ise de sosyal sermayenin bir yansıması olarak taziye kültürü Türk toplumunun tabii canlılığını ve dayanışmasını korumaktadır. Netice itibariyle sosyal sermayenin etkisiyle, taziye kültürünün yaşamakta olduğu Türkiye'de, yas danışmanlığının kurumsal bir hizmete dönüşmesi gecikmektedir. Ancak modernleşen toplum ve kent hayatı, bu sosyal sermayenin sürdürülebilirliğini azaltmaktadır. Bu sebeple kurumsal bir hizmet olarak yas danışmanlığının uygulandığı Almanya örneği, Türkiye'ye örnek teşkil edebilmesi ve uygulamaya yeni açılımlar sağlayabilmesi amacıyla çalışmaya konu olmuştur.

Anahtar Kelimeler: Sosyal Sermaye, Taziye, Yas, Yas Danışmanlığı JEL Sinıflandırması: I38 


\begin{abstract}
Condolence culture as an accumulation of social capital is an important matter in the Turkish tradition. It is known that the condolence culture has, especially in psychological, social and spiritual areas, curative, rehabilitative and improving effects on people who are in a grief process. Condolence ceremonies in Germany are performed by a limited number of family members and close circle. However, in Germany, professional grief counselling for the patients who have terminal diseases as well as for their families, especially in hospitals and nursing homes, are widespread. Assistance for the terminally ill, and grief counselling for their surrounding aim at comforting them in the face of their physical and psychological ordeal through spiritual care and ministry. All patients in Germany are entitled to humane terminal care and grief counselling. Although the grief counselling in Turkey is not yet formed in a corporate/professional form, the condolence culture as a reflection of social capital guards the natural vitality and the solidarity in the Turkish society. The impact of social capital, a result of condolence cultures that live in Turkey, delays the transformation of grief counseling into a professional service. However, social modernization and urbanization reduce the sustainability of this social capital. Therefore, the implementation of grief counseling as a professional consultancy service in Germany can set an example for Turkey, and can provide new insights into the practices mentiond in this study.
\end{abstract}

Keywords: Social Capital, Condolence, Grief, Grief Counseling

Jel Classification: I38

\title{
GİRIŞ
}

Sosyal sermaye kavramı Bourdieu için önemlidir ve ona göre "sosyal dünya, birikmiş bir tarihtir." Sosyal sermaye zaman içinde birikebilir, aynı zamanda "kurumsallaştırılabiliı" para ve mülkiyet hakları, akademik dereceler için de kullanılabilir (Bourdieu, 1983, s. 193).

Sosyal sermaye, toplum için sosyal yardım maliyetlerini azaltmakla kalmayıp aynı zamanda ilişkisel ağlar aracılığıyla da destek sağlamaktadır. Sosyal sermaye etkileşimi, modern toplumlarda da komşuluklar, arkadaş çevresi, dernekler gibi ilişki şekilleri sayesinde hareketliliğin ve ağların arttırılması ile gelişmektedir. Putnam'a göre sosyal sermaye, derneklerdeki topluluk girişimlerinin, karş1lıklılığı güçlendirdiği ve güven inşa ettiği gönüllü 
birlik anlamına gelmektedir. Düşük sosyal sermayeli bir toplumda, sorunların ve çatışmaların çözümünde güven ve iş birliği yetersiz kaldığı için, mülkleri korumada ve devlet kurallarını düzenlemede yasa ve polis gücü daha büyük bir önem taşımaktadır (Bourdieu, 1983, s. 193).

Türk geleneğinde bir sosyal sermaye birikimi olarak ele alınan taziye kültürü; yıllardır süre gelen karşılıklı ilişkilerin, ağların, yardımlaşmanın, dayanışma ve güvenin tesis edildiği bir ürün olarak ortaya çıkmaktadır.

Ölüm, vefat eden bireyin yakınları tarafından kabullenilmesi zaman alan bir olgudur. Ölümün, ölenin yakınlarında bırakmış olduğu hissiyat olan "yas" yaşamın kaçınılmaz bir gerçeği olarak durmaktadır. Yas sürecindeki bireye ailesinin, arkadaşlarının, sosyal yönden ilişkili olduğu kişilerin desteği hiç şüphesiz bireyin yalnız olmadığının bir göstergesidir. Yaslı bireylerin duygularının açığa çıkması bazen konuşma yoluyla gerçekleşebilmektedir. Başkaları ile konuşarak acıların işlenmesi, acıyla başa çıkmakta başarılı olmayı sağlayabilmektedir. Bu bağlamda profesyonel olarak devreye giren "yas danışmanlığı," yas sürecindeki bireyleri kederden kurtarmak amaciyla değil, bu bireylerin yaşadıkları kaybı ve üzüntüleri yaşamlarının bir parçası olarak kabul etmelerine ve yaşamlarına yeniden uyum sağlamalarına yardımcı olmak amaciyla verilen bir hizmettir (Morgenthaler, 2012). Söz konusu hizmet sayesinde, yaşanmış olan yas sürecinden sonra bireylerin güçlenmeleri ve hayatlarını idame ettirebilmeleri daha kolay olmaktadır.

Avrupa'da yas danışmanlığı, yaslı bireylerin, sosyal ve psikolojik yönden tekrar güçlenebilmesi için, çeşitli uygulamalara sahip bir mesleği ve bir sektörü temsil etmektedir. Yas danışmanlığı, Sigmund Freud'un psikodinamik kuram çalışmaları, (1856-1859), Melanie Klein'in depresif pozisyonlar kuramı (1856-1960) ve Yorick Spiegel'in psikodinamik başa çıkma mekanizmaları (1935-2010) çalışmaları ile mesleki zeminini oluşturmuştur (Rechenberg-Winter ve Fischinger, 2010, s. 36).

Almanya Yas Danışmanları Birliği'ne göre Almanya'da, cenaze merasiminden ev ziyaretlerine kadar uzanan, yaslı bireylere yönelik yas refakati hizmeti, bireyin sosyal ve psikolojik yönden sağaltımına katk1 sunmaktadır. Almanya genelinde yas danışmanlığı meslek eğitimi alan 
personele yönelik süpervizyon eğitimleri verilirken, sağlik ve sosyal meslek gruplarına dâhil olan terapist, hemşire, sosyal çalışmacı ve sosyal pedagoglar da yas danışmanlığı sertifika programlarından yararlanmaktadır. Bu programlardan her y1l, iki binin üzerinde katılımc1 faydalanmaktadır. Güncelde Almanya'da asıl ve ek iş olarak mesleğini icra eden yas danışmanları, maaşlarını bağlı bulundukları hizmet kuruluşunun anlaşmalı olduğu sigorta şirketinden saat ücreti bazında almaktadırlar. (Trauerbegleitung, 2019). Türkiye'de ise bu durum yakın aile ilişkileri, arkadaş çevresi, akrabalar aracılı̆̆ıyla sürdürülmeye çalışılmaktadır. Ancak, bireyin sosyal yaşantısını veya psikolojik yönden ruh sağlığını olumsuz yönde etkileyen durumlar karşısında profesyonel yardım devreye girmektedir (Kurter ve Mattis, 2015).

Taziye geleneği, Türk toplumunda önemli bir yere sahip olup köken olarak sosyal yardımlaşmanın, dayanışmanın ve acıyı paylaşmanın bir örneğidir. Kültürel bakımdan her milletin, her coğrafyanın ve her inanç grubunun taziye uygulamalarında farkl1l1klar görülmekte olup, taziyenin işlevi ve etkisi tartışmaya açık bir konu teşkil etmektedir (Kara, 2016). Örneğin Alman taziye geleneğinde cenaze merasimine katılmak yerine, posta yoluyla taziye evine gönderilen taziye kartı, acılarını paylaştıklarını belirten araçsal bir destektir. Vefat edenin yakınlarının, bir davetle onun anısına toplanıp konuşmalar yapması duygusal bir destektir. Diğer taraftan, bu taziye toplantılarında ölen için yemek yenilip, içilmektedir (Morgenthaler, 2012).

Türk geleneğinde ise yaslı eve, komşu ve akrabalar tarafindan yiyecek ve içeceklerin getirilmesi, helva yapılması, dualar okunması gibi uygulamalarla taziye evine maddi-manevi destek verilmektedir. Elif Kara'nın yapmış olduğu çalışma kapsamında, Muş Alparslan Üniversitesi öğrencilerine yaşadıkları memleketlerindeki taziye gelenekleri ile ilgili ödev verilmiştir. $\mathrm{Bu}$ çalışmada Urfa, Şırnak, Muş, Maraş, Elâzığ, Adana, Tarsus, Ağrı ve Hatay illerine ait taziye alışkanlıkları incelenmiştir. Çalışmanın sonuçlarına göre taziye evleri ve çadırları, insanları bir araya getiren unsur olarak önem arz etmektedir. Aynı zamanda ölen kişinin adına yapılan hayırlar, okunan yasin sureleri, taziye evindeki yakınlara yedirilen yemekler, ölümün 
kabullenildiğini ve sorumlulukların yerine getirildiğini gösteren uygulamalar olarak görülmektedir (Kara, 2016, s. 251-270).

\section{SOSYAL SERMAYE KAVRAMI}

Sosyal sermaye kavramı ilk kez 1916 ve 1920'de Lyda Judson Hanifan tarafından kullanılmıştır. 1939'da Norbert Elias tarafından, daha sonra Frankfurt Okulu'nun temsilcileri ve Theodor W. Adorno tarafindan kullanılmıştır. Pierre Bourdieu, biriken sermayeyi nesnel veya içselleştirilmiş bir biçimde açıklayarak üç sermaye türünü birbirinden ayırır: Ekonomik sermaye, kültürel sermaye ve sosyal sermaye. Bunlara ek olarak yaşam tarzı farklılıkları ile saygınlık kazandıran sembolik sermaye söz konusudur. Bireyler ve sınıflar, toplumdaki habitus ve sermaye kaynakları içinde bir konumda yer almak için savaşırlar. Sosyal yapının sınıflara ayrımı, dört sermaye tipinin bertaraf edilmesi ile belirlenir (Bourdieu, 1983, s. 195).

Tüm sermaye biçimleri Bourdieu'ye göre, sosyal değişimin alt biçimleridir. Sosyal sermayenin gücü kültürel ve ekonomik faktörlerle birleşir, belirli sınırlar içinde birbirlerine dönüştürülebilir. Bourdieu için sosyal sermaye, bir ülkenin seçkinleri gibi bir gruba ait olmaktan ve bu grubun üyelerini kendi amaçları için desteklemekten gelen güçtür. Sosyal sermaye, diğer ikisi gibi birinin sosyal sınıflar ve gruplar içindeki statüsünü pekiştirmek veya arttırmak için kullanılır. Bourdieu'ye göre sosyal sermaye, kariyer, iktidar ve refahın sadece bireysel performansa değil, aynı zamanda grup ilişkileri açısından diğer faydalı bağlantılara dayandığından emin olmaya yardımcı olan ilişki ağından türetilmiştir (Braun, 2002). Sosyal sermaye, toplumda bir arada yaşayan insanların temel ihtiyaçlarından biri olan ait hissetme duygusunu tatmin etme gibi bir işlevi yerine getirmektedir. Bireyler bu duygu sayesinde kendilerini evlerindeymiş gibi rahat hissederler. Toplumun ortak hafızasında yer alan yaşanmış olaylar, savaşlar, mücadeleler, sevinçler insanları ortak bir aidiyet duygusu ile bir arada tutmaya yarayan yatırımlardır (Aydemir, 2011, s. 94-97). Topluluk duygusu ve sosyal sermaye araştırmasına göre bir akraba veya tanıdık insan için yardım istenecek kişi ya da kurumların arasında ailesi, komşuları, polis, muhtar ve arkadaşları ilk sırada yer almaktadır. Diğer unsurlar ise manevi temelli mevlit ve dini 
sohbetler olabilmektedir. (Aydemir, 2011, s. 124-128). Bu ritüeller, zamanla geleneksel sistemlere yerleşerek kişilerin gündelik hayatlarına yansıyan kültürel alışkanlıklara dönüşmektedir (Aydemir, 2011, s. 191).

Coleman'a göre sosyal sermaye, "doğumla kurulan ilişkilerde" başlangıç göstermekte, akrabalık bağları ile devam etmektedir. Zaman içerisinde göç, boşanma, iletişimsizlik gibi nedenlerle kopuklukların yaşandığ 1 bu bağlar, sosyal sermayenin niteliğinin de değişmesine neden olmaktadır. (Field, 2003, s. 157). Coleman, sosyal sermayeyi aile ve topluluklarda, çocukların ve gençlerin sosyal ve bilişsel gelişimlerini sağlayacak bir kaynak olarak görmektedir (Şahin, 2010, s. 10).

Sosyal sermaye; din, dil, inanç, tarih, kültür, yardımlaşma, örf, adet ve gelenek olarak bir araya gelen ortak davranış biçimidir. Sosyal, siyasal, ekonomik ve kültürel sermayesi olmayan toplumların sağlıklı gelecek inşa etmesi söz konusu olamamaktadır. İslam coğrafyasında yaşanan çatışmaların temel unsuru hâline gelen etnik milliyetçilik ve mezhepçilik, Müslümanların değerlerine zarar vermektedir. Bir iletişim dili olarak ortaya çıkan sosyal sermaye ise insanlar arasında muhabbeti ve güveni artırmaktadır. Bunu, İslam dininin peygamberi Hz. Muhammed'in "selamı yayınız" hadis-i şerifinden anlamak mümkündür (Altınöz, 2015).

\subsection{Sosyal Sermaye ile Güven Arasındaki Manevi İlişsi}

Sosyal sermaye kavramı, özel mülkiyet veya para gibi somut maddi şeylerin dışında, daha çok insanlar arası sosyal münasebetler açısından bir anlam taşımaktadır. Bir başka ifadeyle sosyal sermaye; insanların günlük hayatta aralarında geliştirdikleri samimiyet, iyi niyet, arkadaşlık, yakınlık gibi güven telkin edici yaklaşımlarla, toplumda sosyal hizmetlerin kültürel olarak kendiliğinden oluşmasına yardımcı olmaktadır. Dolayısıyla sosyal sermaye, hemen her türlü iş birliğine ve yardımlaşmaya imkân veren güçlü sosyal normların varlığı olarak anlaşılabilmektedir (Aydemir, 2011).

Sosyal münasebetler zincirinde karşılıklı yardımlaşma ve dayanışmaya dayalı organizasyonu ve iş birliğini kolaylaştıran ağlar, normlar ve değerler vardır. Bütün bu norm ve değerlerin başında el-emin sıfatı bulunmaktadır. Yani İslam peygamberinin ahlaki vasfi olan ve herkes tarafindan 
benimsenmesi gereken bir değer olan "güvenilirlik" gelmektedir. Kişisel güvenin, kişiler arasında bir ağ şeklinde genişleyerek toplumsal bir boyuta ulaşması ile birlikte, sosyal hayatta sağlıklı ve kalıcı dayanışmalar oluşmakta ve bu sayede toplumsal barış ve gelişme daha sağlıklı bir şekilde yürütülebilmektedir (Köylü, 2012).

Dolayısıyla güven ortamının tesisi ile yeniden şekillenen bütün değerler ve olumlu davranışlar (sadakat, karşılıklı anlayış, hoşgörü, yardımseverlik, sosyal ahlak, sosyal fedakârlık), güçlü sosyal sermaye olarak kendisini göstermekte ve âdeta kurumsal/profesyonel sosyal hizmetleri ikame etmektedir (Aydemir, 2011).

Bir araştırmaya göre, Türkiye'de güvene dayalı sosyal sermaye potansiyeli hayli düşük seviyelerde seyretmektedir. Mesela, Konya ili örneğinde genel güven oranı \%16,8 olarak tespit edilmiştir. Genel anlamda 'insanlara güven duyulabilir mi?' sorusuna verilen cevap ile bir güven endeksi oluşturulduğunda dünya geneli ortalaması \%26 iken, bu oran Konya' da \%6,4 'dür. Ne var ki Türkiye'de güven duygusu; aile, akraba ve komşuluk gibi özel alanlarda daha güçlü bir şekilde kendisini göstermektedir (Aydemir, 2011, s. 189).

\section{MANEVİ SOSYAL HIZMETLER BAĞLAMINDA YAS VE YAS DANIŞMANLIĞI}

Modern dünya, ölümü günlük hayatın bir parçası olmaktan çıkarmıştır. Bunun anlamı, yeni jenerasyonun ölüm olayıyla artık fazla yüz yüze gelmemesi ve ölen kişiyle yakından ilgilenme fırsatlarının az olmasıdır. Çünkü ölenlerin ekseriyeti yaşadığı muhitten/evinden ziyade artık hastanelerde son nefesini vermektedir. Bu durum elbette pek çok insanı ve özellikle ölenin yakınlarını ürkütmekte, endişelendirmekte ve korkutmaktadır. Çünkü; evinde, tanıdıkları ve sevdiği kişiler arasında ölmekle; bilinmedik bir ortamda, üstelik hiç beklemedik bir anda ölmek, aynı durumlar değildir. Diğer yandan ölüm olayı, her bir bireyin hayatında her gün yaşanmamakta ve ölen kişi de en kısa sürede defnedilmektedir. Bütün bu sebeplerden dolayı ölüm olgusu, soğuk ve ürkütücü bir hadise olarak karşımıza çıkmaktadır (Köylü, 2017, s. 185-205). 
Manevi sosyal hizmetlerin vasıtalarından olan keder danışmanlığı veya başka bir isimlendirme ile yas danışmanlığı, insanların başta ölüm olmak üzere kayıp deneyimi ya da beklenen kayıp deneyimi ile başa çıkmalarına yardımcı olmaktadır. Danışman, yas yaşayan bireyin yas durumuyla yüzleşmesi, kabullenmesi ve üstesinden gelebilmesi için konuşma terapisi eşliğinde uygulamalar gerçekleştirerek hizmet vermektedir.

Herhangi bir kayı/ölüm sonrası, insanların duygusal olarak üzgün hissetmesi, yas sürecinin bir parçasıdır. Bu süreçte birey çeşitli günlük gereksinimlerini ihmal edebilmekte, bireyde olumsuz davranışlar gelişebilmektedir. Bireyin hayatını normal ve sağlıklı bir şekilde devam ettirebilmesi için, bir psikolojik danışmana başvurması gerekebilmektedir. Bu durumda danışılan kişinin bir manevi danışman olması da mümkündür (Kara, 2016, s. 260).

Ani veya şiddetli bir ölümle sevdiği yakınını kaybeden ve yas tutan kişiler için gerekli psikolojik ve sosyal desteğin yeterince sağlanamadığı durumlarda depresyon gibi ruhsal çöküntüler baş göstermekte; kişi, yoğun bir manevi desteğe ihtiyaç duymaktadır. Burada özellikle aile ortamında, genellikle mümkün olmayan bir refakat desteğinin yokluğu ve uzun vadeli desteğin olamayışı, yas danışmanına başvurmayı gerekli kılmaktadır. Yas tutan kişilerin yaşadığı kayıp durumlarına sebep olarak şu örnekler verilebilir:

- Belirsiz kayıp durumları (ortadan kaybolma),

- Tabu kayıpları (intihar, kürtaj),

- Küçük yaştaki bireylerin ölümü (çocuklar, torunlar),

- Stresli ilişkiler,

- Dramatik ölümler (uçak kazası, kitle paniği),

• Ölüme sebebiyet vermek (sarhoş sürücü, yarışçılar),

- Engelli yakınının bakım sorumluluğu,

- Travmatik olaylar (savaş, deprem),

- Sosyal ağların eksikliği (özellikle sosyal izolasyondan etkilenen insanlar) (Rechenberg-Winter ve Fischinger, 2010). 


\section{ALMANYA'DA TAZIYYE GELENEĞİ VE YAS DANIŞMANLIĞI}

Çalışma kapsamında bu bölümde, ölüm sonrası yerine getirilen işlemlerin Almanya' daki seyri konu edilmektedir. Bu sebeple cenaze işlemleri arasında yer alan defin yani ölüyü gömme, taziye süresince yerine getirilmesi gereken işler içinde ilk sıralarda yer almaktadır. Bu sebeple öncelikle bu konu işlenmiş, ardından taziye kültürüne geçilmiştir. Son olarak da yas danışmanlığı konusu, eğitimin verilişi ve hangi vakalara yönelik hizmet verildiği gibi bilgilerle işlenmektedir.

\subsection{Almanya'da Cenaze İşlemleri ve Taziye Kültürü}

Almanya'da mezarlık düzenlemesi yasasına göre mezarlık için "sonsuz kullanım" garantisi yoktur. Mezarlıklar zaman içerisinde nakledilebilir, genişletilebilir veya kaldırılabilir. Federal Alman Mezarlıklar Birliği tarafından yapılan açıklamaya göre her yıl, Katolik ve Protestan mezheplerine mensup 500.000 civarında Hristiyan vatandaş gömülmektedir. Cenaze işlemleri, ölen kişinin inancı doğrultusunda yapılmakta ve örnek uygulamalar şart koşulmamaktadır. Ölen kişi bir dini cemaatin üyesi olmamışsa veya dini bir cenaze töreni istenmiyorsa genellikle ücretsiz bir cenaze töreni veya bir konuşmacı tarafından yönetilen bir cenaze hizmeti verilebilmektedir. Cenaze töreni geleneksel olarak üç bölümden oluşmaktadır: Cenaze evindeki taziye, kilise veya şapeldeki hizmet ve mezarlıktaki taziye. Kilisede, ölen kişinin hayatının hatırası için konuşma yapılır, dua edilir ve ayinler yapılır (Friedrich, 2018). Söz konusu hizmetler, kayıp yaşayan bireyin üzerindeki sorumlulukları alması münasebetiyle yas danışmanlığı hizmetinin başlangıç aşamasını oluşturmaktadır.

Alman mezarlık yasalarına göre mezarlık zorunluluğuna ek olarak tabutla gömülme yükümlülüğü bulunmaktadır. Avrupa ve Almanya'da gömme kültürü son yıllarda büyük değişikliklere uğramıştır. Güncelde, geleneksel gömme biçimlerinin yerini, bireyselleştirilmiş gömülme biçimleri almıştır. Prensip olarak Almanya'da yasalara göre ancak özel izinle gerçekleştirilen cenaze törenleri aşağıdaki gibidir: 
- Ceset krematoryumda yakı1ır ve bir "Urne" (toprak kap) içerisinde külleri saklanır. Bu küller bir ağacın köküne, mezarlık duvarının nişlerine, denize veya gökyüzüne serpilmek suretiyle doğaya karışması sağlanır. İsteğe bağlı olarak bu küllerin bir hatıra olarak özel formla pırlantaya dönüştürülme işlemi yapılmaktadır (Klie, 2008, s. 22).

- Almanya'da nehirde yakılarak gömülmeye yasal olarak izin verilmemektedir. Ancak özel bir izinle Hollanda veya İsviçre gibi ülkelerin nehirlerinde (Örneğin Maas nehri) gömülebilirler. Bir diğer yaygın bir gömü geleneği olarak da merhum Hindistan'da, geleneksel olarak halkın önünde yakılır ve daha sonra Ganj nehrine teslim edilir.

- Diğer gömü formu ise Alkali hidroliz (resomasyon) ile cesedin çözülmesi ve sıvılaştırılması veya şoklanarak kompostlama yoluna gidilmesidir.

- Kişinin isteğine bağlı olarak tüm bedeni bilimsel ya da tıbbi amaçlarla bilim dünyasına bağışlanmaktadır.

- Mezar taşına isminin yazılmasını istemeyen kişiler anonim olarak gömülebilirler (Brück, 2012, s. 17).

\subsection{Almanya'da Yas ve Yas Danışmanlığı}

Yas danışmanlığı, yaşamı tehdit eden durumlarla birlikte görülen sorunlarla karşı karşıya olan hastaların ve ailelerinin ağrılarını, fiziki, psikososyal ve manevi (spritüel) diğer sorunlarını erken dönemde belirleyip, kusursuz bir biçimde değerlendirip tedavi etmek suretiyle, bu ailelerin hayat kalitesini geliştiren bir yaklaşımla gerçekleştirilmektedir (WHO, 1990).

Sigmund Freud'un 1917'de "Keder ve Melankoli" üzerine yazdığ1 klasik monografiden beri psikoloji bilimi ve psikiyatristler, yas sahiplerinin duygularıyla yüzleşmeleri gerektiği şeklindeki temel varsayımı paylaşmaktadırlar. Yas tutanların işlenmemiş kederleri, nevroz ve depresyonla sonuçlanabilecek riskler taşımaktadır (Morgenthaler, 2012, s. 73). Bu nedenle yas tutanlarla profesyonel anlamda "yas çalışması" yapılmalıdır. Yas, kayıp gerçekliği ile duygusal ve bilişsel çatışma sürecidir. Örneğin dul insanların bilişsel işlevleri, ölüm olayı ve ölenin anılarıyla 
ilgilidir. Yas çalışmasının işlevi, merhumla olan duygusal bağları yeniden tanımlamak ve onu geçip giden bir parça olarak yaşamına entegre etmektir.

Ölü yakınının yalnız bırakılmaması bir sosyal dayanışma örneğidir. Yaslı bireyler, günümüzde yakın çevresinden toparlanması, güçlü olması yönünde telkinler almaktadır. Ancak yas sahibinin yaşamın getirdiği doğal bir süreci yaşaması, gerekirse psikolojik destek alması olağan bir durumdur (Bundesverband Trauerbegleitung, 2019).

Tarihi süreçte bazı toplum ve kültürlerde acının dışa vurumu zayıflık veya inançsızlık olarak kabul edilmiştir. Bu sebeple gayet insani ve doğal olan yas duygusu, bir tabu olarak görülmüş ve bastırılması yoluna gidilebilmiştir. Ancak modern yaşamın bir gereği olarak terapi modellerinin gelişmesi ile, yas duygusunun ve acının dişa vurulmasına daha fazla olanak sağlanmıştır. Özellikle, ünlü İsviçreli psikiyatrist Elisabeth Kübler-Ross'un modeli olan ve "hayata tutunma," "ölüm ve ölmek üzerine," “yaşam dersleri” adlı çalışmalar; dürtüleri yeniden düşünmeye, harekete geçirmeye ve dürtüler üzerinde çalışmaya imkân vermiştir (Morgenthaler, 2012, s. 73). Zaman içerisinde huzurevi, palyatif bakım ve ölü yakınlarına eşlik edilmesi ile giderek artan hareket, zamanla toplumsal farkındalığa dönüşmüş ve bir meslek hâline gelmiştir. Batı'da 1980'lerden beri refakatçi gruplar ve -refakatsiz- kendi kendine yardım grupları, yas kafeleri kurulmuştur ve bu hareketler bağlamında yas turları düzenlenmektedir (Trauart, 2019).

Almanya genelinde yas danışmanlığı eğitimi, Federal Almanya Yas Danışmanlığı Birliği (Deutsches Federal Verein für Trauerbegleitung) bünyesinde verilmektedir. Özel yas danışmanlığı meslek eğitim kursları ise 36 ay süren eğitim modülleri ile seminer ve uygulamalar eşliğinde verilmektedir. Bu eğitim sonunda alınan sertifikalar tüm Almanya genelinde yasal meslek statüsünde tanınmaktadır. Almanya'da 2007 yılında Federal Yas Danışmanlığı Çalışma Topluluğu tarafından, yas danışmanlığı üzerine kalite güvencesi standartları getirilmiştir. Meslek mensuplarına ek olarak; terapistler, tıpçılar, psikologlar, sosyal çalışmacılar, hemşireler, geriatrist ve manevi danışmanlar yas danışmanlığı yapabilmektedirler (Trauart, 2019). 
Ölüme refakat hizmetleri kapsamında palyatif bakım, bakıma muhtaç hasta ve ailesinin yaşam kalitesine odaklıdır. Bu bakım, bireylerde görülen acı ve diğer belirtileri kontrol etme, sosyal, duygusal ve manevi ihtiyaçları gidermeyi amaçlamaktadır. Palyatif bakım, özellikle iyileştirilemeyen ciddi hastalıklar için önemlidir ve hastaların sadece fiziki, hissî, sosyal değil manevi (spiritüel) yönlerini de dikkate alan geniş kapsamlı bir bakım yaklaşımıdır. Almanya' da palyatif bakım programları; kronik ve hayatı tehdit edici hastalığı olan ve bu sorunlarla yaşayan fertlerin sayısındaki artış sebebiyle ve sağlık profesyonellerinin, hastaların nitelikli bakımlarına yönelik ilgilerinin artması sonucunda son yıllarda hızla gelişmiştir. Maneviyat; tedavi, rahatlama ve huzur duymaya yönelik etkileri açısından önemli bir kaynak olarak değerlendirilmektedir. Özellikle terminal dönemdeki hastalara sağlanan manevi refakat hizmetleri, Almanya'da öncelikli ihtiyaçlar arasında yer almaktadır (Smith, 2000, s. 129-130).

\section{TÜRKIYYE'DE TAZIYYE GELENEĞİ VE YAS DANIŞMANLIĞI}

Çalışmanın bu kısmında Türkiye'deki taziye kültürünün, uygulama örnekleriyle, hangi motivasyonlarla yaşatıldığına bakılarak, dini motifleriyle birlikte anlatılmaktadır. Sonrasında ise mevcut uygulama olan Manevi Rehberlik ve Destek Hizmetleri, yas danışmanlığı kapsamında anlatılmaktadır.

\subsection{Türkiye'de Cenaze İşlemleri ve Taziye Kültürü}

Anadolu geleneğinde, ölümden sonra gerçekleştirilen uygulamaların başında ölünün gözlerinin kapatılması, çenesinin bağlanması, odasının penceresinin açık tutulması gibi işlemler yapılmaktadır. İslam inancının bir gereği olarak imam eve gelerek ölü için Kur'an okur. Camilerde sala okutularak tanıyan herkese vefat haberi duyurulur (Ersoy, 2002). Çeşitli inanışlar, sosyo-kültürel yasın tepkileri konusunda da belirleyici olabilmektedir. Ağıt yakma ve dövünme bir inanışa göre uygun iken, diğer inanışa göre uygun olmayan davranış şekilleridir. Diğer bir örnekte ölen kişinin eşyalarının muhafaza edilmesi normal sayılırken diğer bir kültürde 
ölenin eşyalarının ihtiyaç sahiplerine dağıtılması makbuldür. Anadolu'da taziye ziyaretleri ve mevlitler, sosyal destek sağlarken aynı zamanda ölümü kabullenmeye yardımcı olabilmektedir (Apaydın, 2017, s. 22).

Bunun yanında ölenin arkasından onun sağlığında yapamadığı dinî vecibeler yapılmakta veya onun adına yoksullara sadaka verilmektedir. Defin işlemi öncesi ölünün yıkanması, kefenlenmesi, tabuta konmasından mezara konulmasına kadar tüm işlemler yardımlaşma ve dayanışma içinde gerçekleştirilmektedir. Yas tutan aile yakınları içsel duygularını; koyu renkli giyinme, fazla yememek, radyo veya televizyon açmamak gibi çeşitli dışavurumlarla göstermektedirler. Ölüyü anma ile ilgili olarak Anadolu Türklüğünde İslam kültürü çerçevesinde, vefatın ilk gecesinde ve vefatı takip eden ilk Perşembe akşamı Kur'an okutulup üçüncü gününden sonra yas süreci sona ermek suretiyle sabır sürecine geçilmektedir (Ersoy, 2002).

Devamında ise haftası, kırkı ve elli ikisinde cenaze sahibi tarafindan mevlit okutulur. Vefattan sonraki ilk Ramazan ve kurban bayramlarında ise "kara bayram" olarak nitelendirilen matem havası görülmektedir (Ersoy, 2002). Tüm bu uygulamalardan yola çıkarak cenaze törenlerine sosyolojik açıdan bakıldığı zaman, bütün bu ritüellerin örtük bir işlevi yerine getirdiği ve arka planda toplumsal yardımlaşma ve dayanışmayı geliştirdiği görülmektedir. Cenaze evine yakınlar ve komşular tarafından yiyecek ve içecek getirilmesi sosyal yardımlaşmanın örneğidir. Diğer yandan İslam inancında gömülmek esastır. Buna göre;

- Cenaze kaldırma yani defin işlemleri mevtanın ölüm gününde veya ertesi gün gerçekleşmelidir.

- Mezarlık yönü Mekke (kıble) ile yüzleştirilir.

- Cenaze, kefenle tabutsuz olarak mezara konulur.

- İslam'da cesedin kreasyonuna (yakılmasına) izin verilmemektedir.

- Mezar henüz başka bir gömünün gerçekleşmediği "bakir" toprakta olmalıdır (Gassmann, 2017). 
Tüm bu işlemler ölüye sağlanan, "ebedi bir dinlenme hakkı"dır. Diğer taraftan Müslümanlarda mezar süslemeleri veya mezar bakımı, dinen zorunlu olmadığ 1 için yaygın değildir.

\subsection{Türkiye'de Yas ve Yas Danışmanlığı}

Yas, değer verilen bir şeyin kaybedilmesi durumundan yola çıkarak ömür boyu devam etme potansiyeline sahip bir duygudur. Ebeveynler için evladını yitirmek aynı zamanda anne baba rolünün de yitirilmesi anlamına gelmektedir. Yasın tepkileri; kaybedilenin yakınlığı, kim olduğu, ölüm biçimi ve yaşı gibi unsurlarla değişim göstermektedir. Çeşitli deyimlerle yas çağrışımı yapılmaktadır: "yaka yırtmak, yanıp ağlamak, yere kapanmak, yüreği kararmak, yüreğine ateş düşmek, yüreğini dağlamak, taşlara dövünmek, karalar bağlamak, ciğerini dağlamak” bütün bu deyimler dışında, kökeni Şamanizm ve Bektaşiliğe kadar dayanan geleneklerde ölenin kuş olup uçtuğu benzetmesi yapılmaktadır (Kurter ve Mattis, 2015).

Türk toplumunun kayba bakışı İslam temelli inanışlarla birlikte değerlendirildiğinde Müslümanlar için "sabır” olgusunun ve inanışının yas sürecine yardımcı olduğu görülmektedir. Taziye geleneği dâhilinde olan taziye çadırları, 7. ve 40. gün mevlitleri, ikram edilen yemekler gibi bazı ritüellerde hayır işlerinin etkisi büyüktür (Aksöz, 2014, s. 43-61). Tüm bu dini temelli yardımlaşma faaliyetleri birlik ve beraberlik duygusunu geliştirmektedir. Geleneksel toplumlardaki dayanışmanın batı toplumuna göre daha fazla olması, ölüm gerçeğiyle yas sürecinin daha hızlı atlatılabilmesini mümkün kılmaktadır.

Anadolu'nun bazı bölgelerinde ölenin ardından ağıt yakma geleneği devam etmektedir. Bu gelenekte üzüntü halini dile getirme, "ağıt yakma" şeklinde edebi bir boyuta ulaşmıştır. Vefat edenin iyilik hallerinin ve meziyetlerin sıralandığı ağıtta, ölenin ardından güzel yanlarını yâd etmek, yakınları için teskin edici olabilmektedir. Bu geleneği bir nevi meslek edinmiş, ücret karşılığında yapan birtakım insanlar bulunmaktadır (Özel, 2006).

Esas itibariyle taziye/yas dayanışması, manevi sosyal çalışma kapsamına girdiği için gönüllü imamlar veya din görevlileri tarafından 
informel yollarla yapılmaktadır. Ancak kentleşmenin getirmiş olduğu bireyselleşme sebebiyle aile, eş, dost ve akrabalarla bağlar zayıflamıştır. $\mathrm{Bu}$ sebeple yas dönemindeki birey, yalnız kalmakta ve bu süreçteki işlemlerle, maddi ve manevi zorluklarla tek başına mücadele etmektedir. Sosyal sermayenin sunduğu ve içinde güven, ağ ilişkileri barındıran geleneksel taziye kültürünün yetersizliğine eş olarak kurumsal düzenli bir hizmetin olmayış1, yas sürecini daha da zorlaştırmaktadır. Tüm bu sebepler ve değişen toplumsal yapının beraberinde getirdikleri göz önünde bulundurulduğunda Türkiye'deki mevcut durum, yakın zamanda bu alanda da profesyonel bir destek hizmetini gerekli kılmaktadır.

Nitekim son yıllarda "Manevi Rehberlik ve Destek Hizmetleri" kapsamında Diyanet tarafından, 07.01.2015 tarihinde Diyanet İşleri Başkanlığı ve Sağlık Bakanlığı arasında yapılan bir protokol gereğince, ilk etapta 14 hastanede personel görevlendirilmesi yapılmıştır (Diyanet İşleri Başkanlığı, 2015). Adana, Afyonkarahisar, Ankara, Bursa, Çorum, Erzurum, İstanbul, İzmir, Kahramanmaraş, Kayseri, Konya, Ordu, Sakarya ve Samsun görevlendirmelerin yapıldı̆̆ 1 illerdir. 2017 yılına gelindiğinde 16 ilde, 48 hastanede manevi destek hizmeti sunuldu. 2018 yılında ise hizmet verilen il sayısı 38'e çıtı ve toplam olarak 115 hastanede 230 Manevi Destek Görevlisi ile vatandaşlara hizmet sunuldu (Din Görevlileri, 2017)

Geniş anlamda "Manevi Rehberlik ve Destek Hizmetleri," insanlara acıl1, sıkıntılı, üzüntülü, korkulu, yalnız ve ümitsiz hâllerinde ve ani değişmelerle gelen (hastalık, ölüm, ameliyat, sakatlık, afet vb.) kriz durumlarında, onların yanında olmak gibi bir görevi yerine getirmeyi ifade etmektedir. Ayrıca onlara din ve inanç açısından destek olabilmekten; varsa soru ve sorunlarına danışmanlık etmek, âdet ve ibadetlerini yerine getirebilmelerinde rehberlik etmek ve hayatlarına yeni bir anlam verebilmede eşlik etmekten ibarettir (Küçük, 2017).

Manevi Destek Görevlilerinin tamamı üniversite mezunu olup aralarında ilgili alanda yüksek lisans, doktora yapanlar ve yurtdışı tecrübesine sahip olanlar çoğunluktadır. Diyanet İşleri Başkanlığı Eğitim Merkezinde, bu alanda çalışmalar yapmış akademisyen, eğitimci ve Sağlık Bakanlığı personeli 
tarafından verilen ve yaklaşık 200 saati aşan bir eğitim programı ile alanında profesyonel "Manevi Destek ve Rehberlik Görevlileri" yetiştirilmiştir. Eğitim programında hastanelerde görev yapacak görevlilere din psikolojisi, manevi sosyal hizmetler, manevi bakım, hasta ve hasta yakınlarıyla iletişim, pastoral psikoloji ve dua vaizliği gibi birçok konuda eğitimler verilmiştir.

\section{SONUÇ}

Yas danışmanlığ birimleri $\mathrm{ABD}$ ve Avrupa ülkelerinde altmış yıldan daha uzun süredir faaliyet göstermektedir (Kara, 2016, s. 267). Hristiyan inancına göre yeniden dirilişe olan inanç, ölüm gerçeğini kabullenmede kolaylaştırıcı bir unsurdur. Batı dünyasında çeşitli inanışların olduğu var sayılırsa kişilerin kayba olan inancı da yas sürecinde farklılıklar göstermektedir. Aynı zamanda cenaze merasimlerinin kişiselleştirilmesi, talep edenin arzularına göre cenaze hizmetinin verilmesi cenaze hizmetinin ticarileşmesine sebep olmuştur.

Öte yandan yas danışmanlığının Avrupa'da bu kadar revaçta olmasının sebeplerinden biri; bireyselleşmiş toplumdaki insanların aile, arkadaşlık ve akrabalık bağlarındaki kopuk ilişkilerdir. Almanya toplumunda bireyselleşmenin beraberinde getirdiği yalnızlık duygusuyla yas danışmanına yönelimlerin olduğu, aynı zamanda cenaze işleminin bir ticaret hâline geldiği görülmektedir.

Türkiye toplumunda yas sonrası yaşanan acı verici süreç, bireyin içinde bulunduğu yakın çevrenin de etkisiyle aşılmaktadır. Yas süreci dâhilinde üstesinden gelinemeyen olumsuz duygular ve davranışlar değerlendirildiğinde yas danışmanlığının Türk toplumu için uygulanabilir olduğu düşünülmektedir. Türkiye'de yas danışmanlığı, aktif olarak eğitim verilen bir meslek dalı olarak profesyonel bir zemine oturtulmuş değildir. Sağlık ve sosyal meslek örgütlerinin yas danışmanlığı sertifika programları ile söz konusu hizmetin yaygın hâle gelmesi ve profesyonel bir zemine oturtulması mümkün görünmektedir.

Almanya'da var olan yas danışmanlığı meslek dalı, Türkiye'de henüz bir mesleki eğitim seviyesinde verilmemektedir. Ancak psikolojik danışmalık ve rehberlik, psikiyatri ve psikoloji gibi meslek gruplarınca söz konusu 
hizmetin verildiği görülmektedir. Bahsi geçen meslekler dışında son yıllarda Diyanet'in girişimleriyle 'yas danışmanlı̆̆ı' ismi altında olmasa bile bu hizmeti de içine alacak bir şekilde "Manevi Rehberlik ve Destek Hizmetleri" kapsamında birçok hastaneye resmî olarak "Manevi Destek Görevlileri” tayin edilmiştir. Manevi destek görevlileri, hastanelerde ölen hastanın yakınlarına yas danışmanlığına yönelik telkin ve teskin hizmetleri de verme yetkisine sahiptir.

Yas ve yas danışmanlığ konusunu sosyal sermaye göstergeleri açısından ele aldığımızda Türkiye için çelişkili bir durum ortaya çıkmaktadır. Uluslararası mukayesede Türkiye'nin sosyal sermaye dinamikleri; sivil toplum örgütlerine katılım veya insanlara duyulan güven seviyesi gibi başlıklarda arandığında ulusal sosyal sermaye düzeyi düşük çıkmaktadır. Ancak topluluk/komşuluk/akrabalık gibi yakın sosyal münasebetleri kapsayan alanlardaki sosyal sermaye göstergeleri Türkiye'nin lehine olmaktadır. Bu bağlamda aile, din, geleneksel değerler, sosyokültürel imkânlar, tarihî geçmiş ve şahsiyetler ile birlikte düşünüldüğünde zengin bir sosyal sermaye potansiyelinin varlığı görülmektedir (Aydemir, 2011, s. 194).

$\mathrm{Bu}$ doğrultuda sosyal sermayenin yani insani münasebetlerin aile, akraba ve komşuluk ilişkileri açısından Türkiye gibi güçlü olduğu toplumlarda taziye kültürünün daha gelişmiş olduğu, buna bağlı olarak manevi sosyal hizmetler kapsamında yürütülen yas danışmanlığına da daha az ihtiyaç duyulduğu görülmektedir. Ancak değişen hayat koşulları göz önünde bulundurulduğunda, mevcut taziye kültürünün bu alandaki ihtiyacı ne kadar süre daha karşılayacağı öngörülememektedir. Bu sebeple yakın bir gelecekte yas danışmanlığı hizmetinin kurumsal olarak verilmesi gerekliliği ile karşı karşıya gelinmesi ihtimali bulunmaktadır. 


\section{KAYNAKLAR}

Aksöz, İ. (2014). "Kayıp ve Yas,” “Afetler, Krizler, Travmalar ve Psikolojik Yardım”. Özgür Erdur Baker ve Türkan Doğan (Ed.), (s. 43-63). Ankara:

Psikolojik Danışma ve Rehberlik Derneği Yayınları.

Altınöz, F. Y. (2015). “Sosyal Sermaye,"

https://www.milligazete.com.tr/makale/852700/furkan-yilmaz-altinoz/sosyalsermaye adresinden alındı.

Apaydın, S. (2017). “Kayıp ve Yas, Yas Danışmanlığı”. Özgür Erdur ve İdil AksözEfe (Ed.) (1-51). Ankara: Anı Yayıncılık.

Aydemir, M. A. (2011). "Sosyal Sermaye: Topluluk Duygusu ve Sosyal Sermaye Araştırması”. Konya: Çizgi Kitabevi.

Bourdieu, P. (1983). “Ökonomisches Kapital, Kulturelles Kapital, Soziales Kapital”. (Übz): Reinhard Kreckel, “Soziale Ungleichheiten” Göttingen: Soziale Welt Sonderband 2.

Braun, S. (2002). "Soziales Kapital, Sozialer Zusammenhalt und Soziale Ungleichheit”. https://www.bpb.de/apuz/26805/soziales-kapital-sozialerzusammenhalt-und-soziale-ungleichheit? $\mathrm{p}=$ all adresinden alındı.

Brück, M. (2012). “Ewiges Leben und Wiedergeburt: Sterben, Tod und Jenseitshoffnung in Europeischen und Asiatischen Kulturen”, Münih: Herder Verlag.

Bundesverbang Trauerbegleitung. (2019). “Angebot des Bundesverbandes Trauerbegleitung eV”, (BVT) https://bv-trauerbegleitung.de/ adresinden alındi.

Din Görevlileri. (2017). 'Diyanet, Hastanelere 'Manevi Rehberlik' Personel Alımı Yapacak!,”. https://dingorevlileri.com.tr/diyanet-hastanelere-manevirehberlik-personel-alimi-yapacak-h159.html adresinden alındı.

Diyanet İşleri Başkanlığı. (2015). “TC. Diyanet İşleri Başkanlığı ile TC. Sağlık Bakanlığı arasında Hastanelerde Manevi Destek Sunmaya Yönelik İşbirliği Protokolü”.

https://dinhizmetleri.diyanet.gov.tr/Documents/Sa\%C4\%9F1\%C4\%B1k\%20 Bakan1\%C4\%B1\%C4\%9F\%C4\%B1\%20Protokol\%C3\%BC.pdf adresinden alınd1. 
Ersoy, R. (2002). “Türklerde Ölüm ve Ölü İle İlgili Rit ve Ritüeller,”. Çukurova Üniversitesi Türkoloji Araştırmaları Merkezi. 86-101. http://turkoloji.cu.edu.tr/HALKBILIM/41.php adresinden alındı.

Field, J. (2003). “Sosyal Sermaye”. İstanbul: İstanbul Bilgi Üniversitesi Yayınları.

Friedrich, H. (2018). “Braucht es die Kirche für den perfekten Abschied?”. Berliner Zeitung.

Gassmann, D. (2017). "Jungfrauliche Erde, Frankfurter Allgemeine.

https://www.faz.net/aktuell/gesellschaft/menschen/bestattung-von-muslimenteilweise-problematisch-14942392.htmlm adresinden alınd.

Kara, E. (2016). "Yas Süreci ve Dini Danışmanlık,” Dokuz Eylül Üniversitesi Ilahiyat Fakültesi Dergisi, Özel Sayl, 251-270.

Klie, T. (2008). "Performanzen des Todes: Neue Bestattungskultur und kirchliche Wahrnehmung". Stuttgart: Kohlhammer Verlag.

Köylü, M. (2012). “Ölüm Eğitimi, Dini Danışmanlık ve Din Hizmetleri”. Nurullah Altaş ve Mustafa Köylü (Ed.) Ankara: Gündüz Yayıncılık.

Kurter, F. ve Mattis S, j. (2015). "Türkiye'de Uygulamacıların Gözüyle Psikolojik Danışmada Kültüre Duyarlı Olma”. İstanbul: Bahçeşehir Üniversitesi Yayınları.

Küçük, M. (2017). "Bir Psikoloğun Kaleminden Manevi Rehberlik". İstanbul: Ahir Zaman Yayınları.

Morgenthaler, C. (2012). "Lehrbuch Praktische Theologie: Seelesorge". Gütersloh: Gütersloher Verlagshaus.

Özel, Ü. (2006). “Ağıt Yakan Kadınlar” Haber 7.

http://www.haber7.com/yasam/haber/195537-son-nesil-agit-yakan-kadinlar adresinden alındı.

Rechenberg-Winter, P., Esther F. (2010). "Kursbuch systemnische Trauerbegleitung”. Göttingen: Vandenhoeck\&Ruprecht.

Smith, R. (2000). “A Good Death,” BMJ 320, 129-130.

Şahin, M. M. (2010). “Sosyal Sermaye Kuram Uygulama Eleştiri”. İstanbul: Değişim Yayınları. 
Trauerbegleitung. (2019). https://bv-trauerbegleitung.de/ueberuns/entstehungsgeschichte/ adresinden alındı.

Trauart. (2019). "Trauerbegleitung: Ausbildung \& qualifizierung," https://www.trauart.de/trauerbegleitung-ausbildung-2019 adresinden alınd1.

WHO Expert Committee. (1990) "Cancer Pain Relief and Palliative Care," Cenevre: World Health Organization. 